\title{
Utilization of Ceramic Beads for Edible Mushrooms Cultivation
}

\author{
Poyu Huang, Shoji Ohga \\ Department of Agro-environmental Sciences, Faculty of Agriculture, Kyushu University, Fukuoka, Japan \\ Email: ohga@forest.kyushu-u.ac.jp, jesseh0204@gmail.com
}

How to cite this paper: Huang, P.Y. and Ohga, S. (2017) Utilization of Ceramic Beads for Edible Mushrooms Cultivation. Advances in Microbiology, 7, 853-862. https://doi.org/10.4236/aim.2017.712065

Received: November 14, 2017 Accepted: December 23, 2017 Published: December 26, 2017

Copyright $\odot 2017$ by authors and Scientific Research Publishing Inc. This work is licensed under the Creative Commons Attribution International License (CC BY 4.0).

http://creativecommons.org/licenses/by/4.0/

\begin{abstract}
This study examined ceramic beads as a reusable material for cultivation of edible mushrooms. There are 20 species of popular edible mushrooms in Japan all of which were tested. Within the cultivation vessels, $70 \%$ were ceramic beads (diameter $1 \mathrm{~cm}$ ) and $30 \%$ of the nutrient solution. Moreover, the control groups used several types of sawdust, wheat bran, and rice bran with the ratio of 8:1:1 as the substrate. Two sets of substrates were evaluated with the fruit bodies yield. The result indicated that there were 11 species that responded well with the ceramic bead substrate when compared to the traditional sawdust substrate with Agrocybe cylindrica and Pleurotus ostreatus performed the best adding $70 \mathrm{~g}$ more of the fruit bodies. Conversely, nine species responded poorly with the ceramic beads substrate with Auricularia polytricha performed the worst losing $120 \mathrm{~g}$. Ceramic beads as a reusable material for substrates not only provide a clean and controllable environment for mycelium to colonize but also deliver more aeration and water availability inside the cultivation vessels. The application of the ceramic bead cultivation can be viewed as an alternative solution for producing Ophiocordyceps sinensis on the industrial level.
\end{abstract}

\section{Keywords}

Ceramic Bead Cultivation, Edible Mushroom, Ophiocordyceps sinensis, Aeration Availability, Water Potential

\section{Introduction}

In recent years, mushrooms have been drawing much public attention as a source of development for medications and nutraceuticals because of their antioxidants, antitumors, and antimicrobial properties [1]. Aside from their pharmacological features, mushrooms are becoming more essential to the human diet 
due to their nutritional value, high levels of protein and low levels of fat, which could be considered to be a promising food for patients suffering from high cholesterol and obesity [2]. Mushrooms can be cultivated with low cost and low usage of land compared to other agricultural products; consequently, many farmers and manufacturers are turning towards the cultivation of mushrooms. This industry is likely to experience tremendous growth over the next few years owing to the rise in the consumption of food and medical industry. The global mushroom market was valued at over USD 35.08 billion in 2015 and it is expected to reach above USD 59.48 billion in 2021 [3].

Log culture was developed over 1000 years ago in China and Japan and is still popularly used by smaller farmers in local markets. The advantage of log culture is relatively simple to operate and not technically demanding. However, the process is labor-intensive, seasonal, and is restricted by hard-to-meet demands for high productivity [4]. In comparison, sterilized artificial substrate cultivation methods that recycle various agricultural or industrial residues mixed with nitrogen-rich additives as substrates would raise the productivity and decrease the cost of production and pollution [5] [6].

In a sizable substantial mushroom production, substrates preparation is the most critical and expensive step, and demands years of experience, knowledge, and investment in infrastructure [7] [8]. There are many residues that can be used as substrates depending on the availability of places and the supplementations to be used according to the species and nutritional particulars of the residue [6]. Furthermore, the artificial substrate cultivation method relies heavily on completely sterile handling techniques in order to eliminate the level of competitive microorganisms in the materials being prepared [9]. The extent of colonization of the substrate is determined by mycelium extension rates, biomass yield, and enzyme activities, all of which are great influencers for the success of the cultivation [10] [11].

Many mushrooms are efficient bio-degraders of hardwood. However, log-and wood-residues have been overexploited in many areas and the need for diversification is rising [12]. Potential shortages of hardwood residues and possible heavy metal contamination have highlighted the need to identify alternative substrates that are more sustainable for prolonged future use. The objective of the present cultivation method was to examine whether ceramic beads could produce higher fruit bodies yield than the traditional sawdust cultivation as a reusable material.

\section{Materials and Methods}

\subsection{Fungal Strains}

This study tested 20 species of edible mushrooms, which were obtained from the Mushpia Co. Limit., Fukuoka, Japan. All the edible mushrooms and their cultivation conditions are shown in Table 1. All of these strains were isolated from fruit bodies of commercial sources. Strains were maintained on a potato dextrose agar medium (Difco) at $4^{\circ} \mathrm{C}$. 
Table 1. Twenty species of the edible mushrooms and their cultivation conditions.

\begin{tabular}{|c|c|c|c|c|c|}
\hline & Mushroom species & $\begin{array}{l}\text { Various sawdust species and } \\
\text { rice was used as main } \\
\text { ingredient in control substrate }\end{array}$ & $\begin{array}{l}\text { Culture vessel } \\
\text { and weight } \\
\text { of substrate }\end{array}$ & $\begin{array}{l}\text { Period for } \\
\text { spawn run and } \\
\text { temperature }\end{array}$ & $\begin{array}{c}\text { Days for } \\
\text { fructification } \\
\text { and temperature }\end{array}$ \\
\hline A. & Agrocybe cylindrica $^{a}$ & Fagus crenata & Bottle (500 g) & 80 days, $22^{\circ} \mathrm{C}$ & 20 days, $15^{\circ} \mathrm{C}$ \\
\hline B. & Auricularia fuciformis & Fagus crenata & Bag $(2.5 \mathrm{~kg})$ & 80 days, $22^{\circ} \mathrm{C}$ & 20 days, $15^{\circ} \mathrm{C}$ \\
\hline C. & Auricularia polytricha & Fagus crenata & Bottle (500 g) & 80 days, $22^{\circ} \mathrm{C}$ & 20 days, $15^{\circ} \mathrm{C}$ \\
\hline D. & Cordyceps militaris & Rice $^{b}$ & Bottle (100 g) & 80 days, $22^{\circ} \mathrm{C}$ & 20 days, $15^{\circ} \mathrm{C}$ \\
\hline E. & Flammulina velutipes $^{a}$ & Cryptomeria japonica & Bottle (500 g) & 30 days, $15^{\circ} \mathrm{C}$ & 30 days, $7^{\circ} \mathrm{C}^{\mathrm{d}}$ \\
\hline F. & Ganodermalucidum & Fagus crenata & $\mathrm{Bag}(2.5 \mathrm{~kg})$ & 40 days, $22^{\circ} \mathrm{C}$ & 20 days, $15^{\circ} \mathrm{C}$ \\
\hline G. & Glifolafrondosa & Fagus crenata & $\mathrm{Bag}(2.5 \mathrm{~kg})$ & 40 days, $22^{\circ} \mathrm{C}$ & 20 days, $15^{\circ} \mathrm{C}$ \\
\hline H. & Hericiumerinaceus & Fagus crenata & Bottle (500 g) & 40 days, $22^{\circ} \mathrm{C}$ & 20 days, $15^{\circ} \mathrm{C}$ \\
\hline I. & Hypsizygus marmoreus ${ }^{a}$ & Fagus crenata & Bottle (500 g) & 80 days, $22^{\circ} \mathrm{C}$ & 20 days, $15^{\circ} \mathrm{C}$ \\
\hline $\mathrm{J}$. & Lentinula edodes & Fagus crenata & $\mathrm{Bag}(2.5 \mathrm{~kg})$ & 40 days, $22^{\circ} \mathrm{C}$ & 20 days, $15^{\circ} \mathrm{C}$ \\
\hline K. & Ophiocordyceps sinensis & Rice $^{b}$ & Bottle (100 g) & 80 days, $22^{\circ} \mathrm{C}$ & 20 days, $15^{\circ} \mathrm{C}$ \\
\hline $\mathrm{L}$. & Pholiota adiposa & Cryptomeria japonica & Bottle (500 g) & 80 days, $22^{\circ} \mathrm{C}$ & 20 days, $15^{\circ} \mathrm{C}$ \\
\hline M. & Pholiota microspora & Fagus crenata & Bottle $(700 \mathrm{~g})^{\mathrm{c}}$ & 80 days, $22^{\circ} \mathrm{C}$ & 20 days, $15^{\circ} \mathrm{C}$ \\
\hline $\mathrm{N}$. & Pleurotus cornucopiae & Cryptomeria japonica & $\mathrm{Bag}(2.5 \mathrm{~kg})$ & 30 days, $22^{\circ} \mathrm{C}$ & 20 days, $15^{\circ} \mathrm{C}$ \\
\hline O. & Pleurotus diamor & Cryptomeria japonica & Bottle $(500 \mathrm{~g})$ & 30 days, $22^{\circ} \mathrm{C}$ & 20 days, $15^{\circ} \mathrm{C}$ \\
\hline P. & Pleurotus eryngit & Cryptomeria japonica & Bottle (500 g) & 30 days, $22^{\circ} \mathrm{C}$ & 20 days, $15^{\circ} \mathrm{C}$ \\
\hline Q. & Pleurotus ostreatus ${ }^{a}$ & Cryptomeria japonica & Bottle (500g) & 30 days, $22^{\circ} \mathrm{C}$ & 10 days, $15^{\circ} \mathrm{C}$ \\
\hline R. & Pleurotuscystidiosus subsp. abalonus ${ }^{2}$ & Cryptomeria japonica & Bottle (500g) & 30 days, $22^{\circ} \mathrm{C}$ & 20 days, $15^{\circ} \mathrm{C}$ \\
\hline S. & Pleurotuseringi var. tuolienensis ${ }^{a}$ & Cryptomeria japonica & Bottle (500g) & 30 days, $22^{\circ} \mathrm{C}$ & 10 days, $15^{\circ} \mathrm{C}$ \\
\hline $\mathrm{T}$. & Sparassis crispa & Pinusdesifola & Bottle (500g) & 30 days, $22^{\circ} \mathrm{C}$ & 10 days, $15^{\circ} \mathrm{C}$ \\
\hline
\end{tabular}

${ }^{a} A$. cylindrical, F. velutipes, H. marmoreus, $P$. eryngii, P. ostreatus, $P$. subsp. abalonus, $P$. var. tuolienensis were adopted the kinkaki treatment just before the transferring of cultures into low-temperature rooms, but other mushrooms were induced without the treatment. ${ }^{b} 400 \mathrm{~g}$ of rice added with $100 \mathrm{ml}$ of sink milk. 'The culture bottles had $850 \mathrm{ml}$ capacity, and a large-diameter mouth was used for P. microspora cultures. ${ }^{\mathrm{d}} F$. velutipes was allowed to incubate at $5^{\circ} \mathrm{C}$ for another 10 days preceding the fruit bodies development process to produce uniform fruiting initials.

\subsection{Substrate Preparation}

Substrates and growth conditions for 20 mushroom species are summarized in Table 1. The production of the fruit bodies weights were tested on plastic bags and bottles.

As the control group, the plastic bags contained $2.5 \mathrm{~kg}$ substrate, whereas the plastic bottle $(800 \mathrm{ml})$ contained $500 \mathrm{~g}$ substrate. Each substrate contained various sawdust, rice bran, and wheat bran with the ratio of 8:1:1, respectively. All substrates were added in distilled water in order to adjust the moisture content to $30 \%$.

In comparison, diameter one-centimeter ceramic beads were placed in the plastic bottles or bags instead of the substrates, as shown in Figure 1. For the plastic bottle, it would contain $350 \mathrm{~g}$ of ceramic beads and add in $150 \mathrm{ml} \mathrm{nu}-$ trient solution. Furthermore, for the plastic bags, they would contain $1.8 \mathrm{~kg}$ of 


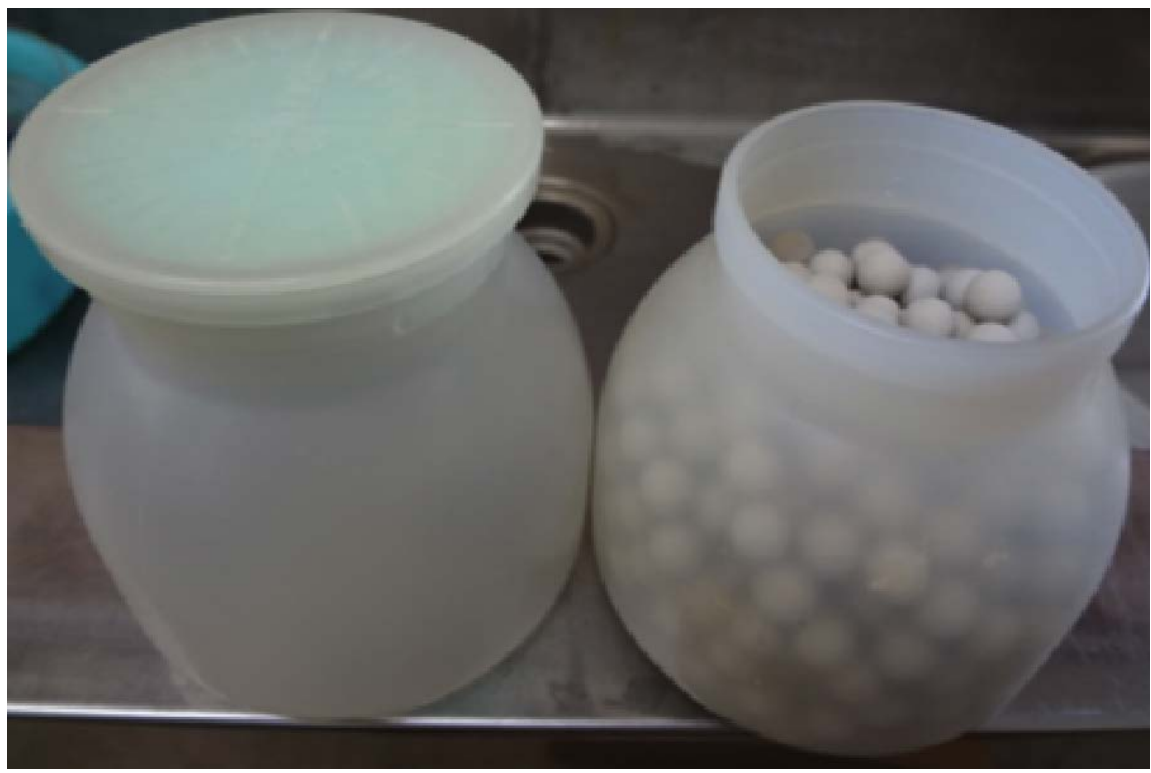

Figure 1. Ceramic beads and bottles used in this experiment.

ceramic beads with $750 \mathrm{ml}$ nutrient solution. Nutrient solution was composed of CMC-Na $50 \mathrm{~g}$, potato powder $20 \mathrm{~g}$, glucose $20 \mathrm{~g}$, yeast extract $2 \mathrm{~g}$, peptone $2 \mathrm{~g}$, $\mathrm{MgSO}_{4} \cdot 7 \mathrm{H}_{2} \mathrm{O} 0.5 \mathrm{~g}, \mathrm{KH}_{2} \mathrm{PO}_{4} 0.5 \mathrm{~g}$ and $1000 \mathrm{ml}$ distilled water. Pholiota microspora was cultivated in a larger bottle filled with $700 \mathrm{~g}$ substrate or $490 \mathrm{~g}$ of ceramic beads with $210 \mathrm{ml}$ nutrient solution. All substrates were added in distilled water in order to adjust the moisture content to $30 \%$.

After the substrate preparation was completed, substrates were autoclaved at $121^{\circ} \mathrm{C}$ for 30 minutes. The substrates cooled to $25^{\circ} \mathrm{C}$ room temperature and then inoculated in sawdust spawn at the surface of the plastic bag and bottle substrates, respectively. Four repetitions were carried out for both control and ceramic bead substrate with the total of 16 replicates per species.

\subsection{Growth Conditions}

All substrates were cultured in the dark during the early phase of fungal growth for 14 days after inoculation, and then were exposed to 500-lux intensity of 12 hours intervals of cool-white fluorescent illumination. Incubation days for mycelial growth and fruiting treatment were specified for various mushrooms, which are presented in Table 1. The substrates in plastic bags and bottles continued to be incubated longer to continue vegetative mycelial growth.

The fructification stimulation, kinkaki treatment (removal of both spawn and the uppermost layer of the medium) was done with the fully matured cultures of Agrocybe cylindrical, Flammulina velutipes, Hypsizygus marmoreus, Pleurotus eryngii, P. ostreatus, Pleurotus cystidiosus subsp. abalones and Pleurotuseringi var. tuolienensis. Chilling treatment (shift down the temperature) was given to all cultures after various incubation days. Total weights of the fruit bodies were measured under the low-temperature conditions for various days as shown in Table 1. 


\subsection{Statistical Analyses}

Identification of statistical differences within treatments was done by Analysis of Variance (ANOVA), followed by Tukey's post hoc test. All the analyses were done with 0.05 significance levels. The analyses were done using Minitab 17 statistical software (Minitab Inc.) and Microsoft Excel. All graphs are presented with standard error bars.

\section{Results}

All the tested species of the edible mushrooms produced fruit bodies on the ceramic bead substrates, shown in Figure 2. We found that 11 species responded better with the new substrate compared to the control substrate. Figure 3 illustrates the fruit bodies weight of the 20 species performing under the ceramic

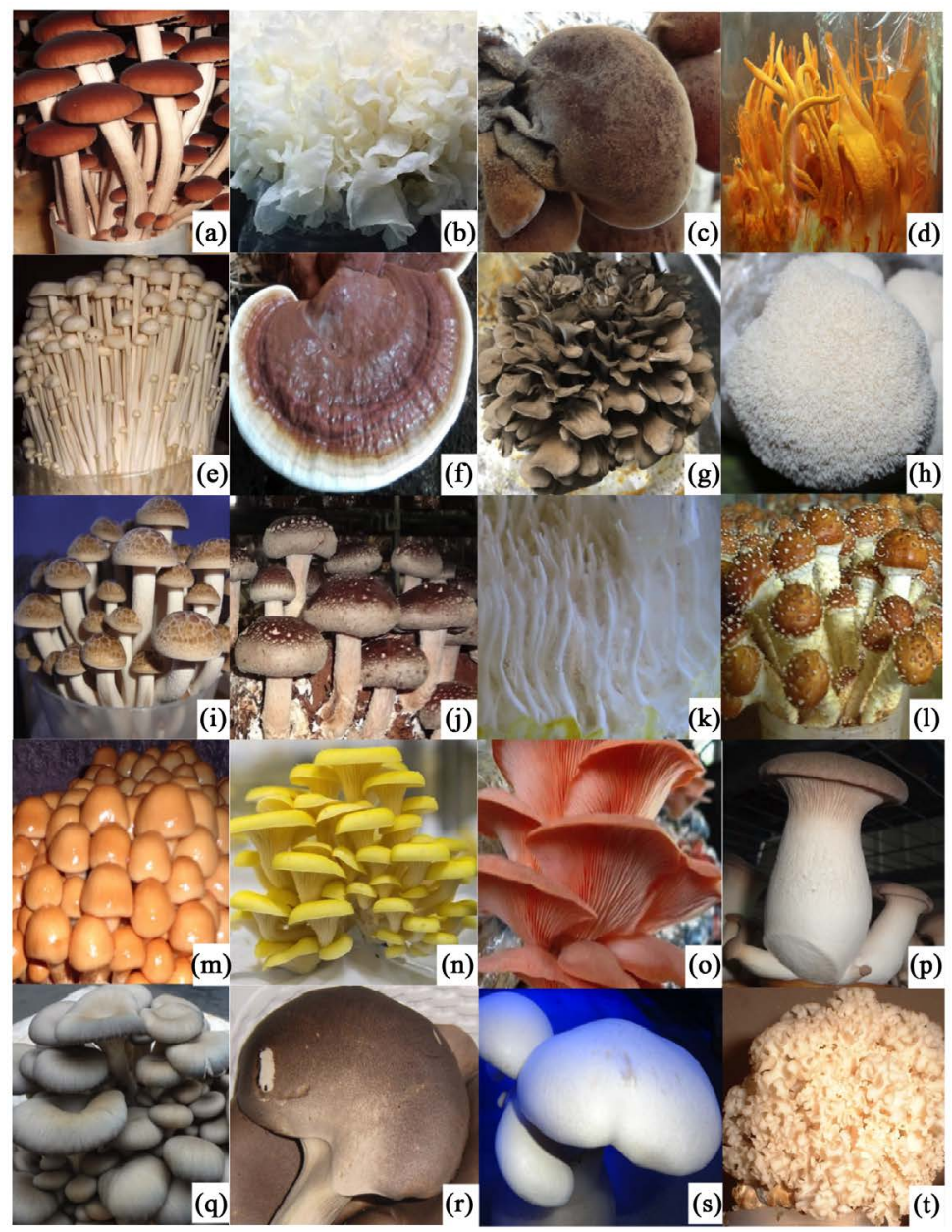

Figure 2. Fruit bodies of the ceramic beads substrate cultivation. (a) Agrocybe cylindrical; (b) Auricularia fuciformis; (c) Auricularia polytricha; (d) Cordyceps militaris, (e) Flammulina velutipes, (f) Ganoderma lucidum; (g) Glifola frondosa; (h) Hericium erinaceus, (i) Hypsizygus marmoreus; (j) Lentinula edodes; (k) Ophiocordyceps sinensis, (l) Pholiota adipose; (m) Pholiota microspore; (n) Pleurotus cornucopia; (o) Pleurotus diamor, (p) Pleurotus eryngii; (q) Pleurotus ostreatus; (r) Pleurotuscystidiosus subsp. abalones; (s) Pleurotuseringi var. tuolienensis; (t) Sparassis crispa. 


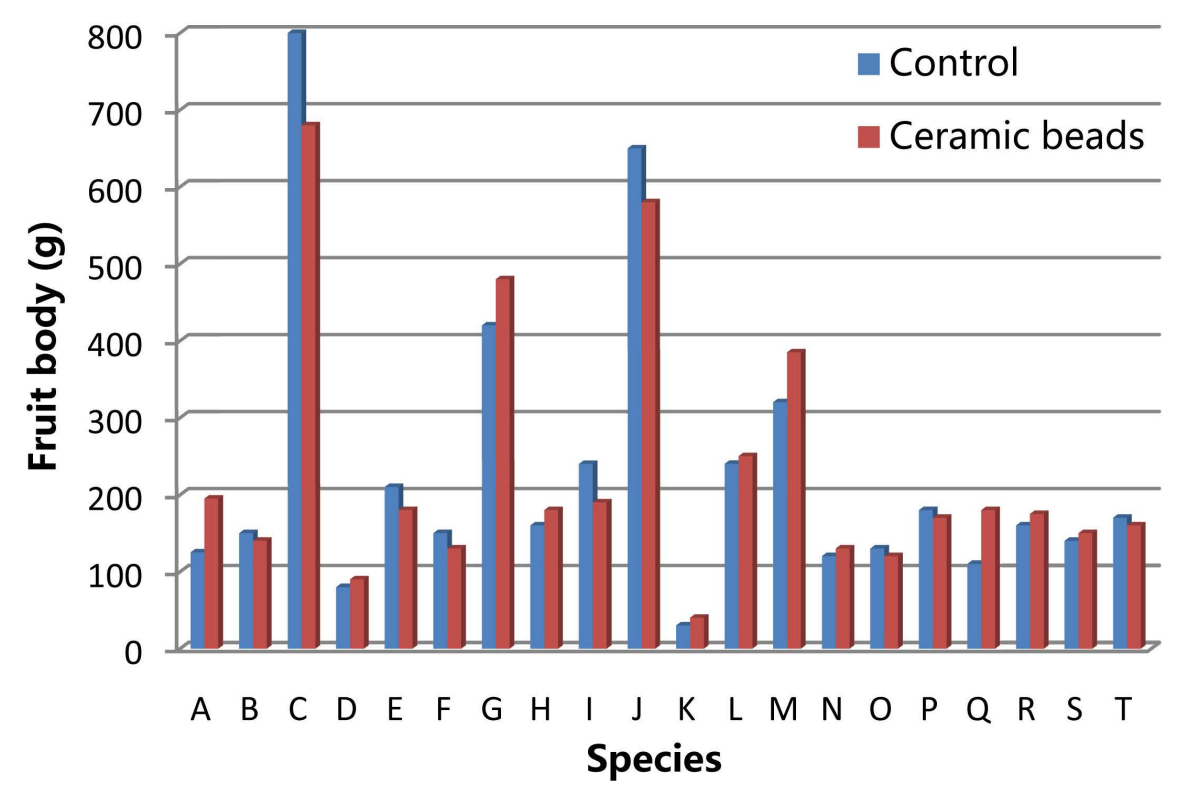

Figure 3. Total fruit bodies weights of all 20 species on ceramic bead substrate comparing to control substrate. Abbreviations refer to Table 1.

bead substrate comparing to the control substrate. Each bar indicates the mean value of 16 replicates measured on the day of fruit bodies maturation. Together A. cylindrical and $P$. ostreatus performed the best with the new substrate adding $70 \mathrm{~g}$ more of the fruit bodies. Both P. microspore and G. frondosa responded second best with the new substrate increasing $65 \mathrm{~g}$ and $60 \mathrm{~g}$ more, respectively. In comparison, $A$. polytricha responded better with the control substrate adding $120 \mathrm{~g}$ more than the ceramic bead substrate. Also, L. edodes did not perform well with the new substrate losing $70 \mathrm{~g}$ more compared to the control substrate.

\section{Discussion}

In recent years, there has been an improvement in public awareness related to forest conservation and production. Starting in 2000, more than 100,000 trees must be felled annually in order to maintain optimal mushroom production level. As mature trees have been declining, irresponsible farmers turn their attention to young trees [12]. It has become a major issue for Chinese forests, where, in $2007,46 \%$ of the world's production of mushrooms was concentrated [13]. Also, for each metric ton of mushrooms produced, at least an equivalent amount of spending on mushrooms' substrate is generated, and this needed to be disposed. This disposal can be very costly due to the disposal charges and taxes on landfill are implemented in many developed countries [12]. Moreover, many mushrooms accumulate metal ions and radioisotopes in the fruit bodies. Waste gathered from industrial or polluted agricultural sources for use in mushroom cultivation may be contaminated by heavy metals to an extent sufficient to render the crop unsuitable for consumption [14] [15]. Those problems have underlined the necessity to acknowledge alternative substrates that are more sustainable for future use. 
Physical conditions for the substrates such as aeration influence, oxygen access, carbon dioxide removal, moisture content, and temperature are significant forces that impact mushroom growth and metabolism [16], especially water and aeration availability [17] [18]. Excellent water availability and substrates interface with the air are expected in the well-matured substrate with high density of mycelium colonization [19]. Ceramic beads as a substrate provided not only solid support but also a clean and controllable environment for mycelium to colonize. The cultivation of ceramic beads was used to develop pure cultures for the growth of microorganisms in both liquid and solid media. Moreover, ceramic beads used in this experiment have tiny holes on the surface, which helps the mycelium to have more aeration and capture more water to increase the water availability inside the cultivation vessels.

Glass beads, which share the similar physical characteristics with the ceramic beads, have been used successfully to culture soil actinomycetes [16] and filamentous Gram-positive bacteria streptomycetes [20]. Redecker et al. illustrated for the first time a cultivation system for arbuscular mycorrhiza fungus using glass beads in order to recover fungal biomass [21]. This system also helps to directly explore the fungal responses to different soil conditions. Chen et al. modified the method for studies on nutrient and trace metal uptake by the arbuscular mycorrhiza fungus [22]. However, there is no research published on the applicability of this approach for cultivating edible mushrooms and their potential for industrial production. Fruit bodies yields are heavily dependent on the nutrition provided. Therefore, further research is still needed on the nutrition requirements for each species in order to reach the optimal yield using the ceramic bead cultivation method.

Moreover, $O$. sinensis, which is one of the most valuable traditional Chinese herbal medicines, is under threat due to the rapid deforestation, climate change, and overharvesting taking place in China, India, and Nepal [23] [24] [25]. Due to the geographical limitation, where $O$. sinensis can only be found at Himalayas, the natural resources are limited and very expensive. It has a broad medical effect, and its function of immunity regulation plays an important role in antitumor effects, organ transplantation and the prevention of kidney, liver, and heart disease [26] [27] [28]. There have been many studies focusing on cultivation of the $O$. sinensis fruit bodies using the artificial substrates [29] [30] [31]. Therefore, the application of the ceramic bead cultivation on $O$. sinensis can be viewed as a promising alternative for the natural products.

\section{References}

[1] Kumar, K. (2015) Role of Edible Mushroom as Functional Foods-A Review. South Asian Journal of Food Technology and Environment, 1, 211-218.

https://www.researchgate.net/publication/304094531_Role_of_edible_mushrooms_ as_functional_foods-A_review

[2] Khatun, S., Islam, A., Cakilcioglu, U. and Chatterjee, N.C. (2012) Research on Mushroom as a Potential Source of Nutraceuticals: A Review on Indian Perspective. 
American Journal of Experimental Agriculture, 2, 47-73.

http://www.journalrepository.org/media/journals/AJEA_2/2011/Dec/1324561208-K hatunetal_2011AJEA492.pdf

[3] Zion Market Research (2017) Global Mushroom Market Is Expected to Reach above USD 59.48 Billion in 2021. Zion Market Research. https://www.zionmarketresearch.com/news/global-mushroom-market

[4] Zied, D.C. and Pardo-Giménez, A. (2017) Technology of Mushroom Cultivation. Edible and Medicinal Mushrooms: Technology and Applications. Wiley-Blackwell, New Jersey, 64-79.

[5] Upadhyay, R.C. and Singh, M. (2011) Production of Edible Mushrooms. In: Hofrichter, M., Ed., Industrial Applications. The Mycota ( $A$ Comprehensive Treatise on Fungi as Experimental Systems for Basic and Applied Research), 10th Edition, Springer, Berlin, Heidelberg, 79-97. https://doi.org/10.1007/978-3-642-11458-8_4

[6] de Carvelho, C.S.M., Sales-Campos, C. and de Andrade, M.C.N. (2010) Mushrooms of the Pleurotus Genus: A Review of Cultivation Techniques. Interciencia, 35, 177-182. http://www.redalyc.org/pdf/339/33913157005.pdf

[7] Vieira, F.R. and de Andrade, M.C.N. (2016) Optimization of Substrate Preparation for Oyster mushroom (Pleurotus ostreatus) Cultivation by Studying Different Raw Materials and Substrate Preparation Conditions (Composting: phases I and II). World Journal of Microbiology and Biotechnology, 32, 190. https://link.springer.com/content/pdf/10.1007/s11274-016-2152-y.pdf https://doi.org/10.1007/s11274-016-2152-y

[8] Chang, S.T. and Miles, P.G. (2004) Mushrooms: Cultivation, Nutritional Value, Medicinal Effect, and Environmental Impact. CRC Press.

https://doi.org/10.1201/9780203492086

[9] Hernández, D., Sánchez, J.E. and Yamasaki, K. (2003) A Simple Procedure for Preparing Substrate for Pleurotus ostreatus Cultivation. Bioresource Technology, 90, $145-150$.

http://www.sciencedirect.com/science/article/pii/S0960852403001184?via\%3Dihub https://doi.org/10.1016/S0960-8524(03)00118-4

[10] Philippoussis, A., Diamantopoulou, P., Papadopoulou, K., Lakhtar, H., Roussos, S., Parissopoulos, G. and Papanikolaou, S. (2010) Biomass, Laccase and Endoglucanase Production by Lentinula edodes during Solid State Fermentation of Reed Grass, Bean Stalks and Wheat Straw Residues. World Journal of Microbiology and Biotechnology, 27, 285-297. https://www.researchgate.net/publication/225507067 https://doi.org/10.1007/s11274-010-0458-8

[11] Philippoussis, A., Diamantopoulou P. and Zervakis G. (2003) Correlation of the Properties of Several Lignocellulosic Substrates to the Crop Performance of the Shiitake Mushroom Lentinula edodes. World Journal of Microbiology and Biotechnology, 19, 551-557.

https://link.springer.com./article/10.1023/A:1025100731410 https://doi.org/10.1023/A:1025100731410

[12] Chiu, S.W., Law, S.C., Ching, M.L., Cheung, K.W. and Chen, M.J. (2000) Themes for Mushroom Exploitation in the 21st Century: Sustainability, Waste Management, and Conservation. The Journal of General and Applied Microbiology, 46, 269-282.

https://www.jstage.jst.go.jp/article/jgam/46/6/46_6_269/_pdf https://doi.org/10.2323/jgam.46.269

[13] Rizki, M. and Tamai, Y. (2011) Effects of Different Nitrogen Rich Substrates and Their Combination to the Yield Performance of Oyster Mushroom (Pleurotus ostreatus). World Journal of Microbiology and Biotechnology, 27, 1695-1702. https://link.springer.com/article/10.1007\%2Fs11274-010-0624-z 
[14] Brunnert, H. and Zadraz ${ }^{\vee}$ il, F. (1983) The Translocation of Mercury and Cadmium into the Fruiting Bodies of Six Higher Fungi: A Comparative Study on Species Specificity in Five Lignocellulolytic Fungi and the Cultivated Mushroom Agaricusbisporus. European Journal of Applied Microbiology and Biotechnology, 17, 358-364. https://link.springer.com/content/pdf/10.1007\%2FBF00499504.pdf

[15] Fischer, R.G., Rapsomanikis, S., Andreae, M.O. and Baldi, F. (1995) Bioaccumulation of Methylmercury and Transformation of Inorganic Mercury by Macrofungi. Environment Science \& Technology, 29, 993-999.

https://doi.org/10.1021/es00004a020

[16] Droce, A., Sørensen, J.L., Giese, H. and Sondergaard, T.E. (2013) Glass Bead Cultivation of Fungi: Combining the Best of Liquid and Agar Media. Journal of Microbiological Methods, 94, 343-346.

http://www.sciencedirect.com/science/article/pii/S0167701213002224?via\%3Dihub https://doi.org/10.1016/j.mimet.2013.07.005

[17] Ohga, S. (1990) Growth Rate of Mycelium of Shiitake, Lentinusedodes, in Relation to Water Potential of Medium. Journal of the Faculty of Agriculture, Kyushu University, 34, 413-420.

https://catalog.lib.kyushu-u.ac.jp/opac_detail_md/?lang=0\&amode=MD100000\&bi bid=23908

[18] Badham, E.R. (1989) Influence of Water Potential on Growth of Shiitake Mycelium. Mycologia, 81, 464-468.

https://www.jstor.org/stable/3760085?seq=1\#page_scan_tab_contents

[19] Ohga, S. (1999) Effect of Water Potential on Fruit Body Formation of Lentinula edodes in Sawdust-Based Substrate. Journal of Wood Science, 45, 337-342. https://link.springer.com/content/pdf/10.1007\%2FBF00833500.pdf https://doi.org/10.1007/BF00833500

[20] Nguyen, L., Kalachova, L., Novotna, J., Holub, M., Kofronova, O., Benada, O., Thompson, C. and Weiser, J. (2005) Cultivation System using Glass Beads Immersed in Liquid Medium Facilitates Studies of Streptomyces Differentiation. Applied and Environmental Microbiology, 71, 2848-2852.

https://www.ncbi.nlm.nih.gov/pmc/articles/PMC1151819/

https://doi.org/10.1128/AEM.71.6.2848-2852.2005

[21] Redecker, D., Thierfelder, H. and Werner, D. (1995) A New Cultivation System for Arbuscular Mycorrhizal Fungi on Glass Beads. Angewandte Botanik, 69, 189-191.

[22] Chen, B.D., Christie, P. and Li, X.L. (2001) A Modified Glass Bead Compartment Cultivation System for Studies on Nutrient and Trace Metal Uptake by Arbuscular Mycorrhiza. Chemosphere, 42, 185-192.

http://pure.qub.ac.uk/ws/files/387430/Chen\%20et\%20al\%202001.pdf https://doi.org/10.1016/S0045-6535(00)00124-7

[23] Dong, C.H. and Yao, Y.J. (2005) Nutritional Requirements of Mycelial Growth of Cordyceps sinensis in Submerged Culture. Journal of Applied Microbiology, 99, 483-492. https://doi.org/10.1111/j.1365-2672.2005.02640.x http://onlinelibrary.wiley.com/doi/10.1111/j.1365-2672.2005.02640.x/abstract

[24] Zhou, X.W., Gong, Z.H., Su, Y., Lin, J. and Tang, K.X. (2009) Cordyceps Fungi: Natural Products, Pharmacological Functions and Developmental Products. Journal of Pharmacy and Pharmacology, 61, 279-291.

http://onlinelibrary.wiley.com/doi/10.1211/jpp.61.03.0002/abstract https://doi.org/10.1211/jpp.61.03.0002

[25] Zhou, X.W., Li, L.J. and Tian, E.W. (2014) Advances in Research of the Artificial Cultivation of Ophiocordyceps sinensis in China. Critical Reviews in Biotechnology, 
34, 233-243. http://www.tandfonline.com/doi/full/10.3109/07388551.2013.791245 https://doi.org/10.3109/07388551.2013.791245

[26] Kuo, Y.C., Tsai, W.J., Shiao, M.S., Chen, C.F. and Lin, C.Y. (1996) Cordyceps sinensis as an Immunomodulatory Agent. The American Journal of Chinese Medicine, 24, 111-125. https://www.ncbi.nlm.nih.gov/pubmed/8874668 https://doi.org/10.1142/S0192415X96000165

[27] Tuli, H.S., Sandhu, S.S. and Sharma, A.K. (2014) Pharmacological and Therapeutic Potential of Cordyceps with Special Reference to Cordycepin. 3 Biotech, 4, 1-12. https://link.springer.com/article/10.1007/s13205-013-0121-9\#citeas

[28] Zhong, S., Pan, H., Fan, L., Lv, G., Wu, Y., Parmeswaran, B., Pandey, A. and Soccol, C.R. (2009) Advances in Research of Polysaccharides in Cordyceps Species. Food Technology and Biotechnology, 47, 304-312. http://www.ftb.com.hr/images/pdfarticles/2009/July-September/47-304.pdf

[29] Chioza, A. and Ohga, S. (2013) Mycelial Growth of Paecilomyces hepiali in Various Agar Media and Yield of Fruit Bodies in Rice Based Media. Advances in Microbiology, 3, 529-536. https://file.scirp.org/Html/4-2270245_40127.htm https://doi.org/10.4236/aim.2013.37071

[30] Chioza, A. and Ohga, S. (2014) Effects of Hot-Water Extract of Paecilomyces hepiali on Hypertension Parameters in Spontaneously Hypertensive Rats. Advances in Microbiology, 4, 436-443. https://doi.org/10.4236/aim.2014.48048 http://www.scirp.org/journal/PaperInformation.aspxPaperID $=46854$

[31] Chioza, A. and Ohga, S. (2014) A Comparative Study on Chemical Composition and Pharmacological Effects of Paecilomyces hepiali and Wild Ophiocordyceps sinensis. Advances in Microbiology, 4, 839-848.

http://www.scirp.org/journal/PaperInformation.aspxPaperID=50113 https://doi.org/10.4236/aim.2014.412093 